\title{
Academic Libraries and Librarians in the Disruptive Era
}

\author{
Toong Tjiek Liauw \\ Academic Librarian \\ Petra Christian University, Indonesia \\ Email: anugraha@petra.ac.id
}

The past few decades have introduced us to the Digital Natives, a generation born in the 1980s, who have been familiar with Information and Communication Technology (ICT) and the myriads of ICT products since the day they were born. The last decade has also made us familiar with numerous disruptive innovations and technologies that have now been so pervasive in our daily lives and have 'threatened' many established practices on how we conduct our lives and businesses, such as ride-sharing (Uber, Grab, etc.), accommodation-sharing (AirBnb), and the block chain technology that has been applied in more and more aspects of life, with Bitcoin as one of its applications in the crypto currency sector.

Those changes and disruptions have not spared the higher education (HE) sector. Nowadays HE institutions need to take into account the characteristics of the Digital Natives, and various disruptive innovations and technologies if they want to remain relevant and stay ahead of the competition in the sector. All aspects of $\mathrm{HE}$ - including academic libraries, are not immune to these changes and disruptions. In the past, academic libraries have tended to play their roles as the storehouse of information and the provider of space for individual learning. The advent of the Digital Natives and disruptive technologies have led some in the HE sector to argue that academic libraries would soon lose their relevance since nowadays information can be accessed digitally from anywhere and at any time. People who believe this line of thinking have given some examples. One of them is the demise of Blockbuster (movie rental) stores in the United States (US) with the emergence of online video/movie streaming services. However, many forget that libraries, including academic libraries, also have their social functions besides their traditional roles as an information storehouse and individual learning space. Due to their social functions, libraries have even been viewed as one of the most democratic spaces that societies have. This is especially true in the case of public libraries, but also - to some extent - true for academic libraries, where they also perform their functions as community hubs.

In responding to the needs of Digital Natives (and the subsequent generations after them) and disruptive technologies, many academic libraries have shifted their emphases away from without abandoning - their traditional roles. They have now put more emphases in their roles as managers of the HE institutions' intellectual outputs and as connectors; connecting people to people and connecting people to ideas. These trends have been visible in the increasing number of academic libraries that have established digital institutional repositories to manage their institutions' intellectual outputs, including the grey literature (reports, student works, and other university records-type resources). Besides showcasing their institutions' intellectual output and 
encouraging public accountability atmosphere in their institutions, the establishments of these institutional repositories have also - to certain extent - created alternative channels in the dissemination of scholarly, as well as semi-scholarly, works to a wider audience in the society.

Also, academic librarians have now started to get involved more and more as partners in the teaching and research life cycle of their academic colleagues. They provide services and consultations to lecturers and/or researchers in navigating the myriads scholarly resources available on the Internet and through online subscription services. They also advise their academic colleagues on related issues, such as research data management, copyright issues of scholarly works, as well as advocating for a more openly accessible scholarly landscape. And since academic librarians tend to talk to researchers from various disciplines, they naturally act as connectors. They connect people to people and people to ideas; facilitating the crosspollination of ideas, including multi-disciplinary approach to learning, teaching, and research. Their role in managing the institution's intellectual assets, too, will naturally make academic librarians connectors of people, and people to ideas. The role as connectors can also been seen in the way academic libraries transform their physical space into more collaborative space that facilitate interactions and exchange of ideas.

As with many things in life, changes are unavoidable. In this disruptive era, the right leadership and vision are needed, both at the library and university administration level. 